\title{
Editorial: Renewable Energy and Oceanic Structures: Part II
}

1 José A.F.O. Correia PhD, MSc, CEng

Researcher, Department of Civil Engineering, Faculty of Engineering, University of Porto, Rua Dr. Roberto Frias, s/n, 4200-465 Porto, Portugal

2 Tiago Ferradosa PhD, MSc, CEng

Assistant Researcher, Hydraulic Structures and Sea Energy Research Group, Department of Civil Engineering, Faculty of Engineering, University of Porto, Rua Dr. Roberto Frias, s/n, 4200-465 Porto, Portugal

3 José Miguel Castro PhD, MSc, CEng Professor, Department of Civil Engineering, Faculty of Engineering, University of Porto, Rua. Dr. Roberto Frias, s/n, 4200-465 Porto, Portugal
4 Dimitrios G. Pavlou PhD, MSc, MEng

Professor, Department of Mechanical and Structural Engineering and Materials Science, University of Stavanger, P.O. Box 8600 Forus, N4036 Stavanger, Norway

5 Abílio M.P. De Jesus PhD, MSc, MEng

Professor, Department of Mechanical Engineering, Faculty of Engineering, University of Porto, Rua Dr. Roberto Frias, s/n, 4200-465 Porto, Portugal
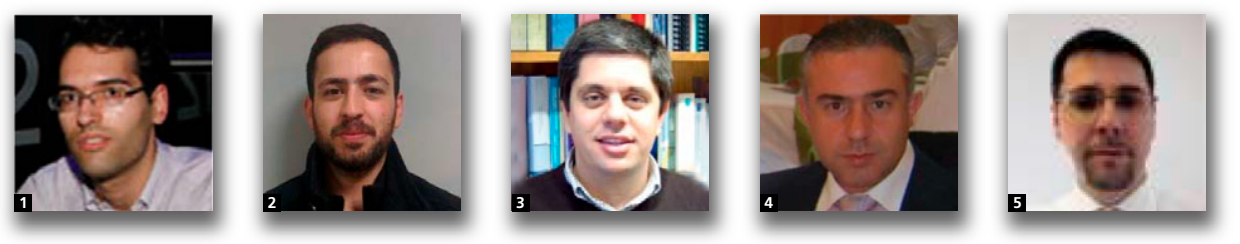

Maritime Engineering covers the investigation on safe and sustainable engineering in the salt-water environment and publishes scientific and technical works regarding the management, planning, design, analysis, construction, operation, maintenance, and applied research related to renewable energy and oceanic engineering. Works from industry and academia are published in this journal conveying advanced research on developing, designing or constructing schemes, as well as good practices in the field.

This issue on Renewable Energy and Oceanic Structures corresponds to the second part of the selected papers from the thematic session with the same name that took place within the International Colloquium on Mechanical Fatigue of Metals at Faculty of Engineering of the University of Porto, on 5-7 September 2018 (Correia et al., 2019). This thematic session (Alessi et al., 2019) was intended to be a forum for discussion of the recent advances in the domain of the structural integrity, inspection, monitoring, repair, maintenance, fatigue, fracture mechanics, structural design, stability, safety, reliability, materials technologies, computational fluid dynamics, renewable energy and environment, in the field of ocean, offshore, polar, arctic, naval, marine renewable energy, subsea, coastal and aquaculture engineering.

The papers in this second thematic issue on Renewable Energy and Oceanic Structures of Maritime Engineering focus on the following topics. Floods \& flood works, hydraulics and hydrodynamics, dredging and reclamation, foundations, fatigue, maintenance and inspection, and risk and probability analysis.

The first paper (Tanim and Akter, 2019) presents an investigation on the application of remote-sensing, particularly significant wave height and wind velocity information, for the complementary development of the storm-surge model. This study aimed to develop a coupled wave-flow model to deal with uncertainties involved in datasets with satellite-derived information to improve storm-surge prediction in the northern Bay of Bengal. Also, the coupled modelling system and the storm-surge process for cyclone Mora were investigated with a series of validation and parametric sensitivity tests.

In the second paper (Dang et al., 2019), the authors proposed a procedure for inspecting welded joints using observed water levels. Furthermore, optimal inspection plans were evaluated by risk analysis, combining failure probabilities and associated expected costs for different events. The authors found that the total expected cost of inspections performed at regular time intervals was generally higher than inspections performed when a certain annual failure probability threshold has been reached.

The paper by Fazeres-Ferradosa et al., (2019) presents a brief review of the scientific and technical challenges in the research 
field of reliability of offshore scour protection. Additionally, a discussion of future research lines was performed with a particular focus in the aim of the Oracle project. Therefore, the recent advances in risk and reliability analysis of offshore scour protection are addressed and framed, and the existing knowledge gaps in the literature were mentioned.

Associated editors appreciate the authors that contributed to this special issue as well as to authors of general papers submitted to the Maritime Engineering journal and would like to thank them for this opportunity to collaborate.

\section{REFERENCES}

Alessi L, Correia JAFO and Fantuzzi N (2019) Initial design phase and tender designs of a jacket structure converted into a retrofitted offshore wind turbine. Energies, 12(4): 659, https://doi.org/10.3390/ en12040659.
Correia JAFO, Ferradosa T, Castro JM, Fantuzzi N and De Jesus AMP (2019) Editorial: Renewable Energy and Oceanic Structures: Part I. Proceedings of the Institution of Civil Engineers Maritime Engineering 172(1): 1-2, https://doi.org/10.1680/ jmaen.2019.172.1.1.

Dang TV, Morato PG, Mai QA and Rigo P (2019) Optimal inspection and repair scheduling for mitre lock gates. Proceedings of the Institution of Civil Engineers Maritime Engineering 172(3): 95-103, https://doi.org/10.1680/ jmaen.2019.10.

Fazeres-Ferradosa T, Taveira-Pinto F, Rosa-Santos P and Chambel J (2019) A review of reliability analysis of offshore scour protections. Proceedings of the Institution of Civil Engineers - Maritime Engineering, 172(3): 104-117, https://doi.org/10.1680/ jmaen.2019.11.

Tanim AH and Akter A (2019) Storm-surge modelling for cyclone Mora in the northern Bay of Bengal. Proceedings of the Institution of Civil Engineers - Maritime Engineering, 172(3): 73-94, https://doi.org/10.1680/ jmaen.2019.1. 